\title{
Freeze-Lining Formation of a Synthetic Lead Slag: Part I. Microstructure Formation
}

\begin{abstract}
MIEKE CAMPFORTS, EVGUENI JAK, BART BLANPAIN, and PATRICK WOLLANTS
Recently, freeze linings have been selected more frequently to protect pyrometallurgical reactor walls, due to a number of advantages over conventional refractory linings, such as a selfregenerating capability and the possibility of operating under high-intensity process conditions. A freeze lining is formed on a cooled reactor wall in a time-dependent temperature gradient. A full description of freeze-lining development, including phase formation as a function of temperature, time, and position, is important in understanding freeze-lining formation mechanisms and may be instrumental for the design of a sustainable freeze-lining concept. Freeze-lining formation is therefore investigated in a synthetic lead slag system: $\mathrm{PbO}-\mathrm{FeO}-\mathrm{Fe}_{2} \mathrm{O}_{3}-\mathrm{ZnO}-\mathrm{CaO}-$ $\mathrm{SiO}_{2}$. Lab-scale freeze linings were produced by submerging an air-cooled probe into liquid slag for different times ranging from 1 to 120 minutes. The freeze-lining microstructures were characterized with optical microscopy, scanning electron microscopy (SEM), and electron probe $\mathrm{X}$-ray microanalysis. The results were compared with the results of reference experiments. The freeze-lining formation of the studied slag system is initially dominated by the formation of glass and a highly viscous liquid. After 1 minute, extensive crystallization occurs and further growth of the freeze lining is determined by the growth of the melilite phase, which forms networking crystals. Because the heat transfer occurs very quickly, these melilite crystals form in undercooled liquid. Because the initial solidification rate is high, mass exchange between the freeze lining and bath affects the freeze-lining growth only when the freeze lining almost reaches its steady-state thickness.
\end{abstract}

DOI: $10.1007 / \mathrm{s} 11663-009-9256-9$

(c) The Minerals, Metals \& Materials Society and ASM International 2009

\section{INTRODUCTION}

SEVERAL pyrometallurgical processes operate with high-intensity conditions, such as a high process temperature, strong convection in the bath, and aggressive process materials. To extend the life of the refractory wall, these processes often use a cooled reactor wall. In the case of extensive cooling, a protecting layer of process material solidifies on the reactor wall. This layer is referred to as a freeze lining. For example, slag cleaning, ${ }^{[1,2]}$ zinc fuming, ${ }^{[3,4]}$ ilmenite smelting, ${ }^{[5-7]}$ and the Hall-Héroult process ${ }^{[8-11]}$ use freeze linings. The stability of the freeze lining has a direct impact on the corrosion of the refractory. In order to control the freeze-lining stability, a study of the freeze-lining microstructure (phase distribution and composition) is important. A study of this type determines the properties of the freeze lining and provides information on the thermal history of the freeze lining and, thus, on

MIEKE CAMPFORTS, formerly Research Assistant, Materials Science Department, Katholieke Universiteit Leuven, is Project Leader, Umicore Research, Olen 2250, Belgium. Contact e-mail: mieke. campforts@eu.umicore.com BART BLANPAIN, and PATRICK WOLLANTS, Professors, are with the Centre for High Temperature Processes, Metallurgy and Refractory Materials, Department of Metallurgy and Materials Engineering, Katholieke Universiteit Leuven, Leuven 3001, Belgium. EVGUENI JAK, Professor, is with the Pyrometallurgy Research Centre, University of Queensland, Brisbane St. Lucia, QLD 4072, Australia.

Manuscript submitted December 19, 2008.

Article published online July 16, 2009. freeze-lining formation and evolution during the process.

In the literature, freeze-lining microstructures have been studied for cryolite salts of the Hall-Héroult process ${ }^{[10,11]}$ and for some industrial nonferrous slags. ${ }^{[12,13]}$ Thonstad and Rolseth ${ }^{[11]}$ studied lab-scale freeze linings of cryolite salt formed under fast and slow cooling rates. At fast cooling, the layer consisted of amorphous material with a composition close to the bath composition. At slow cooling, the layer consisted of cryolite crystals oriented parallel to the heat flux, with a composition close to that of pure cryolite being the primary phase of the studied salt. The authors also studied industrial freeze-lining samples. Here, layers of both slow- and fast-cooled microstructures were observed, indicating that both cooling conditions can occur during freeze-lining formation. Solheim and Støen ${ }^{[10]}$ studied the freeze-lining formation of synthetic cryolite salts. They observed that cryolite dendrites were formed during freeze-lining growth. Here, the freezelining composition deviates from the cryolite composition due to the entrapment of liquid between the dendrites.

Campforts et al. ${ }^{[12,13]}$ studied freeze-lining formation for an industrial nonferrous slag. Lab-scale freeze linings were obtained using the watercooled probe technique. ${ }^{[14]}$ In the microstructure, from the cooled probe to the liquid slag bath, a glass layer is first observed, followed by a glass layer with equiaxial crystals, a layer with columnar crystals, and, finally, a layer of the remaining slag bath. The changing crystal 
morphology and scale in the layers are explained by the continuously changing solidification conditions (solidification rate and temperature gradient at the bath-solid interface) during freeze-lining formation. ${ }^{[15]}$ At the cooled probe side, the slag is rapidly cooled, resulting in the formation of a glass phase. Because the slag is here in immediate contact with the cooled probe and thus, at a low temperature, no further crystallization is observed after this layer is formed. Further from the probe, the slag is cooled more slowly, because the previously solidified slag forms an isolating layer on the probe. Here, the local temperature is higher and further crystallization occurs after the layer has formed. The mass transport and the crystal growth during freezelining formation were also studied. The authors made a distinction between the local mass exchange between glass/liquid and crystals without changing the global composition of the freeze lining (short-range mass transport), and the mass exchange parallel to the heat flux resulting in a global change in the freeze-lining composition (long-range mass transport). In the layers with glass phase and glass with equiaxed crystals, only short-range mass transport is assumed to occur. In the columnar crystal layer, long-range mass transport affects the freeze-lining growth. It is observed that the melilite phase forming large, broad crystals with a small amount of liquid in between the crystals is forced to exchange components with the bath to allow its growth. The olivine phase forms long, thin crystals with a large amount of liquid in between the crystals and can more easily exchange components with the liquid in between the crystals.

Previous research is only a first step toward fully understanding freeze-lining formation. A full description of freeze-lining development, including its thermal history, is not yet available. A next step is to determine this thermal history, more specifically, to determine the bath-freeze-lining interface temperature evolution during freeze-lining formation and the temperature gradient in the freeze lining.

The present research consists of two parts. In part I, freeze-lining microstructures are studied to determine the formation of the freeze lining. More specifically, the present article describes the microstructural characterization of the lab-scale freeze-lining samples and the reference samples of a synthetic lead slag. In part II, microstructural data and thermodynamic calculations are combined to determine the thermal history of the freeze lining. ${ }^{[16]}$

\section{EXPERIMENTAL}

\section{A. Cooled Probe Technique}

The watercooled probe technique is described elsewhere. ${ }^{[12-14]}$ In the present experiments, however, an aircooled probe is used. The experimental procedure is as follows: $3 \mathrm{~kg}$ mixed pure oxide powders are melted in an $\mathrm{Al}_{2} \mathrm{O}_{3}$ crucible in open air. When the targeted bath temperature of $1240{ }^{\circ} \mathrm{C}$ is reached, an initial bath sample is taken with a cold steel rod and quenched in water. Next, the air-cooled probe with two thermocouples fixed at 1 and $2 \mathrm{~cm}$ from the probe is submerged $30 \mathrm{~mm}$ into the bath during $1,5,15,30,60$, and 120 minutes to form a freeze layer, keeping the rotational speed of the crucible $(28.5 \mathrm{rpm})$, the air-flow rate $\left(25 \mathrm{Nm}^{3} / \mathrm{h}\right)$, and the bath temperature $\left(1240{ }^{\circ} \mathrm{C}\right)$ constant. The crucible is rotating to enhance the temperature and composition homogeneity of the bath through forced convection. The effects of the liquid flow rates on the freeze-lining formation mechanisms (i.e., dislodging crystals and changing compositional and temperature gradients) are possible, but have not been investigated. At the end of the experiment, the probe is taken quickly from the bath and the freeze layer is quenched in water. Similar to the initial bath sample, a final bath sample is taken.

\section{B. Reference Experiments}

The initial bath sample of the 1-minute probe experiment was used to perform reference experiments: both isothermal annealing experiments and cooling experiments. For the isothermal annealing experiments, each sample $(0.5 \mathrm{~g})$ was placed in a Pt crucible and held for 60 or 120 minutes at $700{ }^{\circ} \mathrm{C}, 800{ }^{\circ} \mathrm{C}, 900{ }^{\circ} \mathrm{C}$, $1000{ }^{\circ} \mathrm{C}, 1100{ }^{\circ} \mathrm{C}$, or $1200{ }^{\circ} \mathrm{C}$ in air. At the end of the experiment, the sample was quenched in water. For the cooling experiments, each sample $(0.5 \mathrm{~g})$ was placed in a $\mathrm{Pt}$ crucible and melted at $1240{ }^{\circ} \mathrm{C}$ for 5 minutes. Thereafter, the sample was cooled at a rate of $10{ }^{\circ} \mathrm{C} /$ min to reach a constant temperature $\left(800{ }^{\circ} \mathrm{C}, 900{ }^{\circ} \mathrm{C}\right.$, or $1000{ }^{\circ} \mathrm{C}$ ) at which the sample was kept until the total experimental time of 120 minutes (exclusive of the 5 minutes for melting) was completed, followed by quenching the sample in water. Apart from these three experiments, one sample was quenched in water after 15 minutes of cooling at $10^{\circ} \mathrm{C} / \mathrm{min}$. For all experiments, the samples were in contact with air.

\section{Analysis}

All samples were analyzed using light optical microscopy (LOM), scanning electron microscopy (SEM), and electron probe microanalysis (EPMA). The latter was used to measure phase compositions. The SEM was used in backscattered electrons (BSE) mode at a $10-\mathrm{kV}$ acceleration voltage. The EPMA using wavelengthdispersive spectroscopy was performed with a reference current of $30 \mathrm{nA}$ in the willemite standard at a $20-\mathrm{kV}$ acceleration voltage. As standards, anglesite, willemite, hematite, and glaverbel glass were used for $\mathrm{Pb}, \mathrm{Zn}, \mathrm{Fe}$ and $\mathrm{Al}$, and $\mathrm{Si}$ and $\mathrm{Ca}$, respectively.

\section{Thermodynamic Calculations}

Thermodynamic calculations were performed with FactSage, ${ }^{[17]}$ using the FACT53 and FACToxid thermodynamic databases developed for $\mathrm{Pb}$ - and $\mathrm{Zn}$-containing slag systems. ${ }^{[18,19]}$ All calculations were performed for a system in equilibrium with air, because no reduction agent is present and the slag is continuously in contact with air. 


\section{E. Slag}

The synthetic lead slag was made by melting pure powders (less than 0.1 wt pet impurities), $\mathrm{CaO}$ is added as $\mathrm{CaCO}_{3}$. The targeted slag composition is shown in Table I. The slag selection is based on its solidification properties predicted with FactSage and not necessarily on industrial relevance. A predicted liquidus temperature of $1200{ }^{\circ} \mathrm{C}$ was selected to combine sufficient kinetics with limited crucible corrosion and $\mathrm{PbO}$ fuming. Melilite is selected as primary phase, because its $\mathrm{PbO}$ content strongly increases with decreasing temperature in this lead slag. Low melting phases such as $\mathrm{Pb}_{3} \mathrm{Ca}_{2} \mathrm{Si}_{3} \mathrm{O}_{11}$ (further referred to as PCSi) are also desirable to have a temperature indication in the freeze lining. Figure 1 shows the equilibrium solidification path in air for the selected slag predicted with FactSage. When the slag solidifies, melilite $\left((\mathrm{Ca}, \mathrm{Pb})_{2}(\mathrm{Zn}, \mathrm{Fe})(\mathrm{Si}, \mathrm{Fe})_{2} \mathrm{O}_{7}\right)$ is predicted to form at $1200{ }^{\circ} \mathrm{C}$. At $1160{ }^{\circ} \mathrm{C}$, spinel $\left((\mathrm{Zn}, \mathrm{Fe}) \mathrm{Fe}_{2} \mathrm{O}_{4}\right)$ is predicted to become stable and the slag follows the reaction liquid $\rightarrow$ melilite + spinel. With further cooling, $\mathrm{Ca}_{3} \mathrm{Si}_{2} \mathrm{O}_{7}$ and $\mathrm{PbFe}_{10} \mathrm{O}_{16}$ are predicted to form at $990{ }^{\circ} \mathrm{C}$ and $980{ }^{\circ} \mathrm{C}$, respectively, following the reactions liquid $\rightarrow$ melilite + spinel $+\mathrm{Ca}_{3} \mathrm{Si}_{2} \mathrm{O}_{7}$ and liquid $\rightarrow$ melilite + spinel + $\mathrm{Ca}_{3} \mathrm{Si}_{2} \mathrm{O}_{7}+\mathrm{PbFe}_{10} \mathrm{O}_{16}$. At $930{ }^{\circ} \mathrm{C}$, the amounts of melilite, $\mathrm{Ca}_{3} \mathrm{Si}_{2} \mathrm{O}_{7}$, and $\mathrm{PbFe}_{10} \mathrm{O}_{16}$ decrease when PCSi and $(\mathrm{Ca}, \mathrm{Pb})_{2} \mathrm{SiO}_{4}$ are predicted to form, following the reaction liquid + melilite $+\mathrm{Ca}_{3} \mathrm{Si}_{2} \mathrm{O}_{7}+\mathrm{PbFe}_{10} \mathrm{O}_{16} \rightarrow$ spinel $+\mathrm{PCSi}+(\mathrm{Ca}, \mathrm{Pb})_{2} \mathrm{SiO}_{4}$. Finally, all liquid is predicted to solidify at $920{ }^{\circ} \mathrm{C}$.

Table I. Targeted Composition of Synthetic Lead Slag (Weight Percent)

\begin{tabular}{ccccc}
\hline $\mathrm{CaO}$ & $\mathrm{SiO}_{2}$ & $\mathrm{PbO}$ & $\mathrm{ZnO}$ & $\mathrm{Fe}_{2} \mathrm{O}_{3}$ \\
\hline 11.7 & 16.3 & 50.5 & 8.3 & 13.2 \\
\hline
\end{tabular}

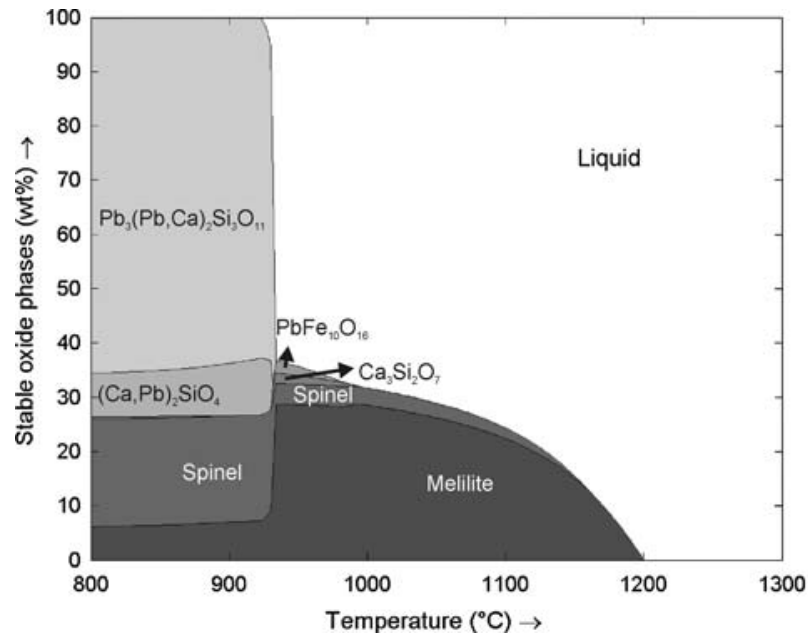

Fig. 1-Equilibrium solidification path for the targeted lead slag composition (Table I) in air predicted with FactSage.

\section{RESULTS}

In this section, the glass phase refers to the state at room temperature. Before quenching, this glass phase was liquid or glass. In the discussion, the state at high temperature is determined.

\section{A. Slag-Bath Samples}

The $\mathrm{Al}_{2} \mathrm{O}_{3}$ content in the slag increases from 0 to 2 to $4 \mathrm{wt}$ pct, as shown in Table II. The microstructures of most slag samples consist of glass phase with some small spinel crystals. Some microstructures contain large melilite and spinel crystals, as shown in Figure 2 for the initial bath of the 1-minute experiment. Around these crystals, the glass is inhomogeneous, consisting of light gray, high- $\mathrm{PbO}$ and dark gray, low-PbO glass.

\section{B. Freeze-Lining Samples}

\section{Thickness of the freeze lining}

The freeze-lining thickness as a function of submergence time is shown in Figure 3. Initially, the freeze lining grows very fast; after 1 minute, its thickness reaches $5 \mathrm{~mm}$ and after 5 minutes, the final thickness is almost obtained. After 30 minutes, the freeze-lining thickness remains stable and steady state is reached.

\section{Microstructure of the freeze lining}

Figure 4 shows the microstructure of the 1-, 5-, 15-, and 120-minute freeze linings. In the microstructure after 120 minutes, six different layers can be distinguished: (1) a glass layer, (2) a glass-with-crystals layer,

Table II. Composition of Initial and Final Bath

\begin{tabular}{lcccccc}
\hline Wt Pct & $\mathrm{CaO}$ & $\mathrm{SiO}_{2}$ & $\mathrm{PbO}$ & $\mathrm{ZnO}$ & $\mathrm{Fe}_{2} \mathrm{O}_{3}$ & $\mathrm{Al}_{2} \mathrm{O}_{3}$ \\
\hline Initial slag & 11.5 & 19.1 & 47.3 & 7.8 & 11.7 & 2.5 \\
Final slag & 11.1 & 19.0 & 48.8 & 6.7 & 10.7 & 3.7 \\
\hline
\end{tabular}

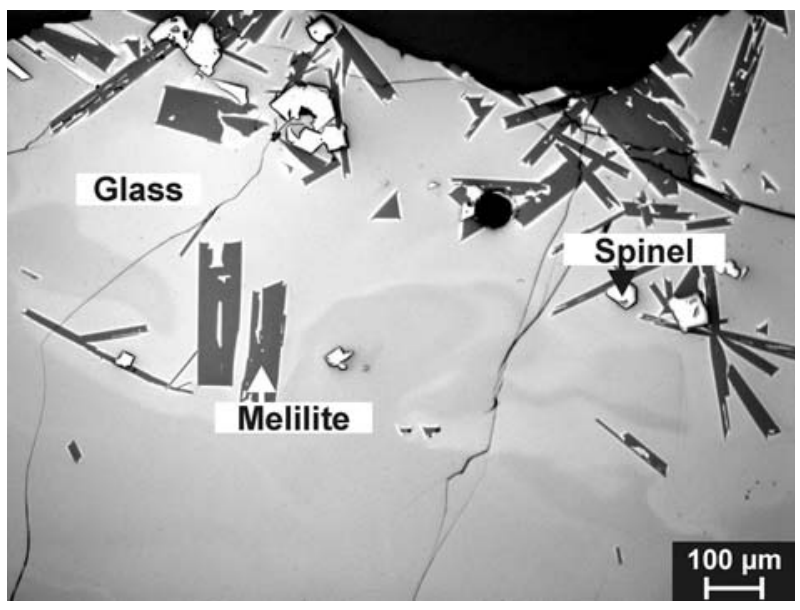

Fig. 2-LOM image of the microstructure of the initial bath sample for the 1-min experiment. 
(3) a crystalline layer, (4) a crystals-in-liquid layer, (5) a sealing-crystals layer, and (6) an entrained-slag-bath layer. The glass layer (1) is observed in all freeze linings

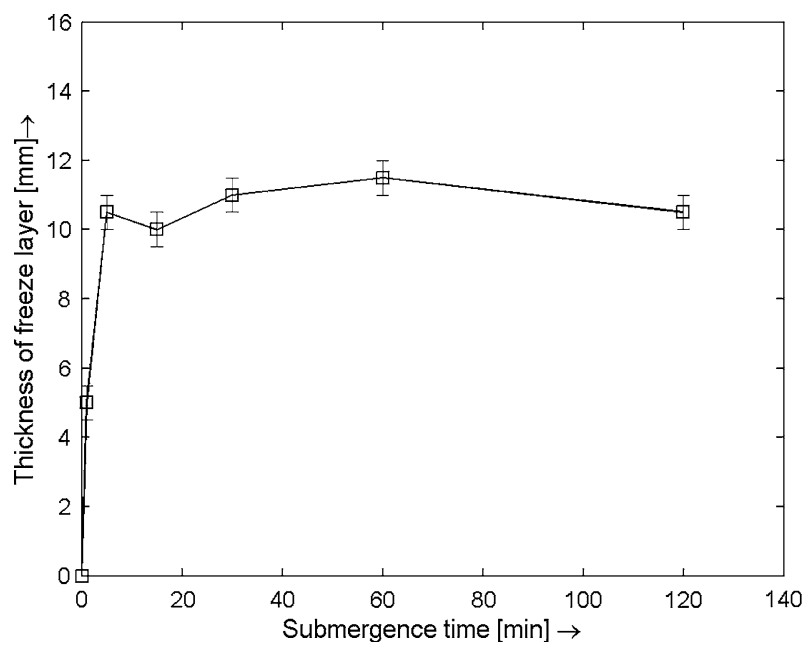

Fig. 3-The thickness of the freeze lining as a function of submergence time. and is located at the probe side. In some microstructures, such as at 1 minute, large melilite and spinel crystals are observed in the glass layer. The composition and the morphology of these crystals are similar to the ones observed in some slag-bath samples (Figure 2). The glass-with-crystals layer (2) is also present in all microstructures. Here, small spinel, melilite, PCSi, and PbFesilicate crystals are observed. For the latter, the exact phase could not be determined, because the crystals are too small. Two types of melilite crystals are observed: large crystals similar to the ones in some bath samples (Figure 2) and small crystals with a high $\mathrm{PbO}$ content. The crystalline layer (3) appears in the microstructure after 5 minutes between the glass-with-crystals (2) and the crystals-in-liquid (4) layers. In the crystalline layer (3), almost no glass is observed between the spinel, melilite, $\mathrm{PCSi}$, and $\mathrm{PbFe}$-silicate crystals. Here, no distinction is made between the small and large melilite crystals, because only one type is observed. This is also the case for layers (3), (4), (5), and (6). The crystals-inliquid layer (4) is observed in all microstructures and is thus formed before the crystalline layer (3). After 1 and 5 minutes, this layer (4) is in contact with the bath, and only melilite and spinel crystals are observed in the
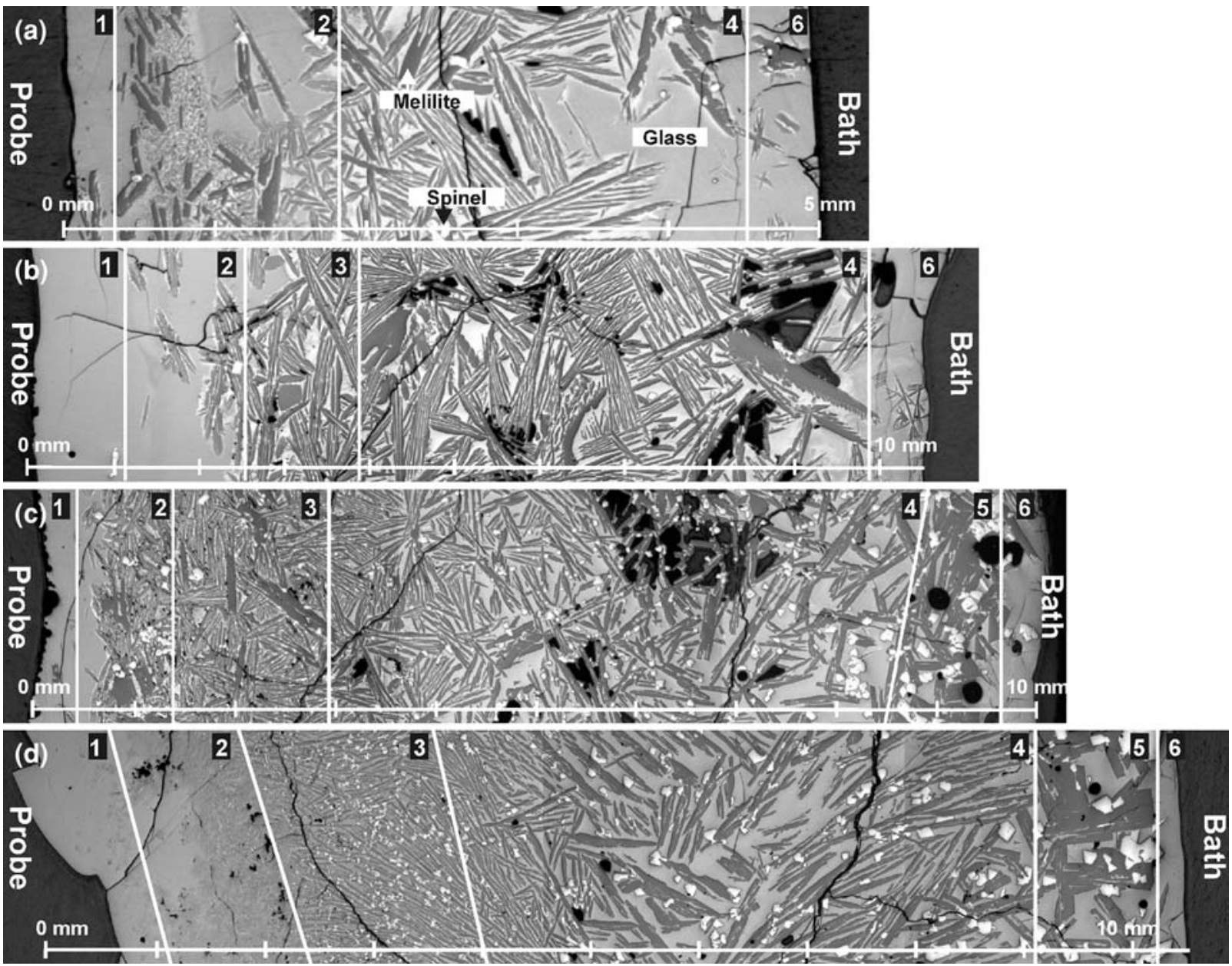

Fig. 4-LOM images of the microstructure of the freeze lining for (a) 1-min, (b) 5-min, (c) 15-min, and (d) 120-min submergence times. Six layers are indicated: (1) glass, (2) glass-with-crystals, (3) crystalline, (4) crystals-in-liquid, (5) sealing-crystals, and (6) entrained-slag-bath layers. The melilite, spinel, and glass phase are indicated in (a). The scale bars indicate the distance to the probe. The distance between two bars is $1 \mathrm{~mm}$. 
samples. After 15 minutes, $\mathrm{PCSi}$ and $\mathrm{PbFe}$-silicate crystals are observed in the glass phase at the bath side. In this layer (4), it is remarkable that the glass phase is brighter (higher $\mathrm{PbO}$ content) at the melilite crystalglass interface than in the middle between two melilite crystals (lower $\mathrm{PbO}$ content). The sealing-crystals layer (5) is only observed in the microstructures after $15 \mathrm{~min}$ utes. In this layer (5), broad and large melilite and large spinel crystals are observed. The size of both crystals increases with time. The entrained-slag-bath layer (6) is observed in all freeze linings and has a microstructure similar to the glass layer (1). The reason for the distinction between a glass-with-crystals layer (2) and a crystals-in-liquid layer (4) is explained in the discussion.

For the short-duration experiments $(15$ minutes and less), it is observed that the glass phase close to the melilite crystals is brighter than the glass further from the melilite crystals in the crystals-in-liquid layer (4). For the 5- and 15-minute microstructures, similar lighter (high $\mathrm{PbO}$ content) and darker (low $\mathrm{PbO}$ content) areas

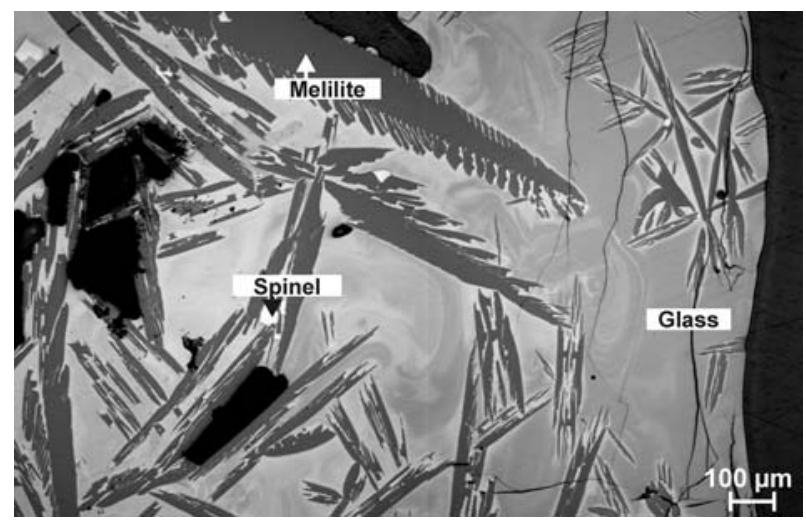

Fig. 5-LOM image of the 5-min freeze-lining microstructure taken at the bath-freeze-lining interface. The glass phase is inhomogeneous. are observed all over the glass at the bath-freeze-lining interface (layers (4) to (6)), as shown in Figure 5 for the 5 -minute microstructure.

\section{Composition of glass and melilite in freeze lining}

The composition of the glass phase strongly changes with the distance to the probe, as shown in Figure 6 for the 5- and 120-minute freeze linings and in Table III for the 120-minute freeze lining. In the glass layer (1), the composition of the glass phase equals the initial bath composition for both freeze linings. In the glass-withcrystals layer (2), the glass composition remains equal to the initial bath composition in the 5-minute experiment; in the 120-minute freeze lining, some scatter appears. At the interface between the glass-with-crystals layer (2) and the crystalline layer (3), the composition of the glass phase changes markedly: an increase in the $\mathrm{PbO}$ content and a decrease in the $\mathrm{CaO}, \mathrm{Fe}_{2} \mathrm{O}_{3}, \mathrm{ZnO}$, and $\mathrm{SiO}_{2}$ content. In the crystals-in-liquid layer (4), the sealingcrystal layer (5), and the entrained-slag-bath layer (6), the composition of the glass phase gradually converges to the end-slag-bath composition with increasing distance from the probe (which is very close to the initial bath composition). Between 6 and $10 \mathrm{~mm}$, a large spread in the glass composition is observed due to the areas with light, PbO-rich glass and dark, PbO-low glass. In the entrained-slag-bath layer (6), the glass composition converges to the final bath composition. For the 5-minute freeze lining, the glass composition in the entrained-slag-bath-layer (6) fluctuates around the final bath composition, as shown in Figure 7(a). For the 120-minute freeze lining, there is a clear composition gradient in the glass phase at the bath side, as shown in Figure 7(b).

The composition in the melilite phase changes strongly with distance to the probe, as shown in Figure 8 for the 5- and 120-minute freeze linings and in Table IV for the 120-minute freeze lining. With increasing distance to the probe, the $\mathrm{PbO}$ concentration

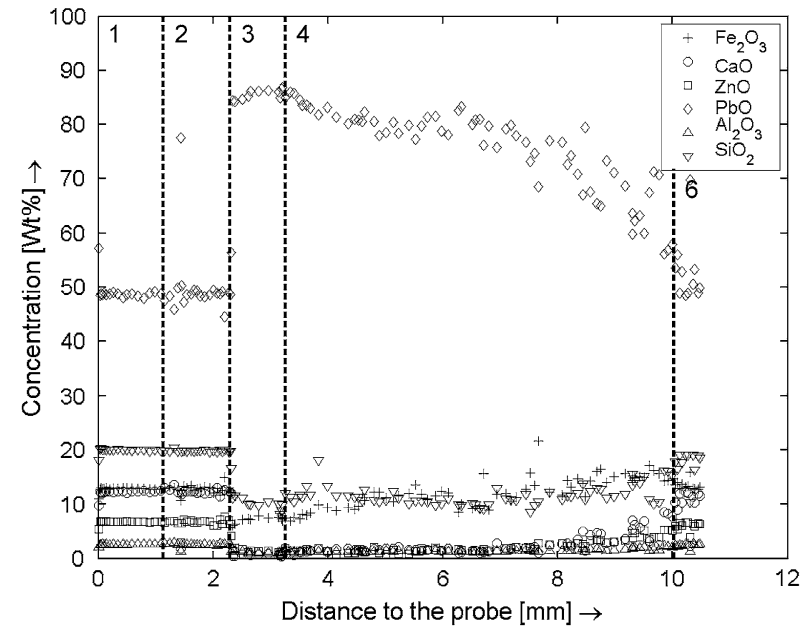

(a)

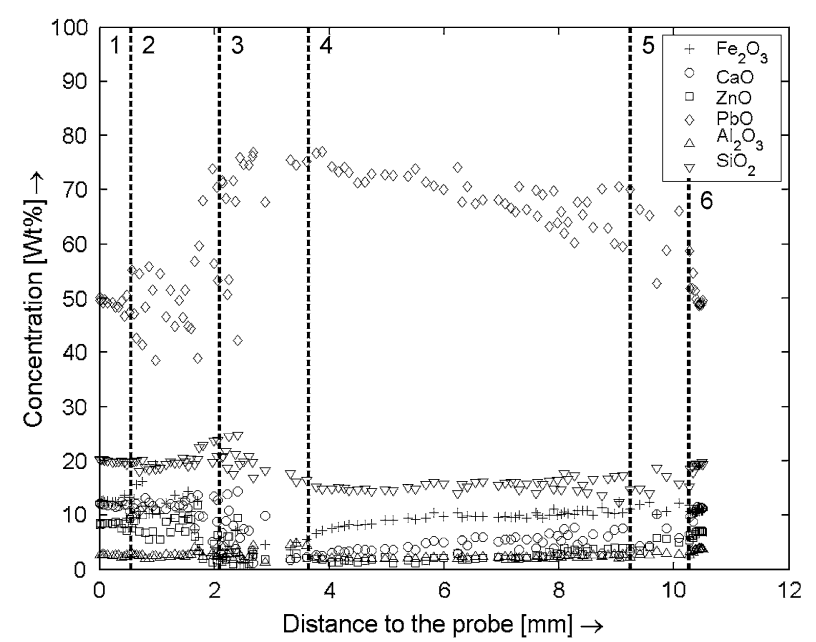

(b)

Fig. 6 - Composition of the glass phase as a function of distance to the probe for (a) 5-min and (b) 120-min freeze lining with the (1) glass, (2) glass-with-crystals, (3) crystalline, (4) crystals-in-liquid, (5) sealing-crystals, and (6) entrained-slag-bath layers. 
Table III. Average Glass Composition \pm Standard Deviation in Six Layers of 120-Minute Freeze Lining

\begin{tabular}{|c|c|c|c|c|c|c|}
\hline Wt Pct & $\mathrm{CaO}$ & $\mathrm{SiO}_{2}$ & $\mathrm{PbO}$ & $\mathrm{ZnO}$ & $\mathrm{Fe}_{2} \mathrm{O}_{3}$ & $\mathrm{Al}_{2} \mathrm{O}_{3}$ \\
\hline (1) & $11.4 \pm 0.1$ & $19.1 \pm 0.2$ & $47.0 \pm 0.3$ & $8.1 \pm 0.2$ & $19.1 \pm 0.2$ & $2.5 \pm 0.1$ \\
\hline (2) & $11.6 \pm 0.9$ & $18.9 \pm 0.7$ & $49.4 \pm 3.1$ & $7.3 \pm 1.3$ & $10.4 \pm 1.5$ & $2.4 \pm 0.3$ \\
\hline (3) & $8.6 \pm 3.3$ & $20.4 \pm 1.9$ & $61.3 \pm 6.8$ & $3.4 \pm 2.2$ & $3.4 \pm 1.7$ & $2.9 \pm 0.7$ \\
\hline (4) & $4.6 \pm 1.7$ & $15.2 \pm 1.2$ & $66.9 \pm 4.1$ & $2.3 \pm 0.8$ & $8.7 \pm 2.1$ & $2.4 \pm 0.6$ \\
\hline (5) & $7.2 \pm 2.3$ & $16.6 \pm 1.7$ & $57.3 \pm 4.6$ & $5.1 \pm 0.9$ & $10.9 \pm 0.7$ & $2.9 \pm 0.4$ \\
\hline (6) & $10.9 \pm 0.6$ & $19.0 \pm 0.5$ & $49.1 \pm 1.5$ & $6.8 \pm 0.3$ & $10.7 \pm 0.2$ & $3.6 \pm 0.1$ \\
\hline
\end{tabular}

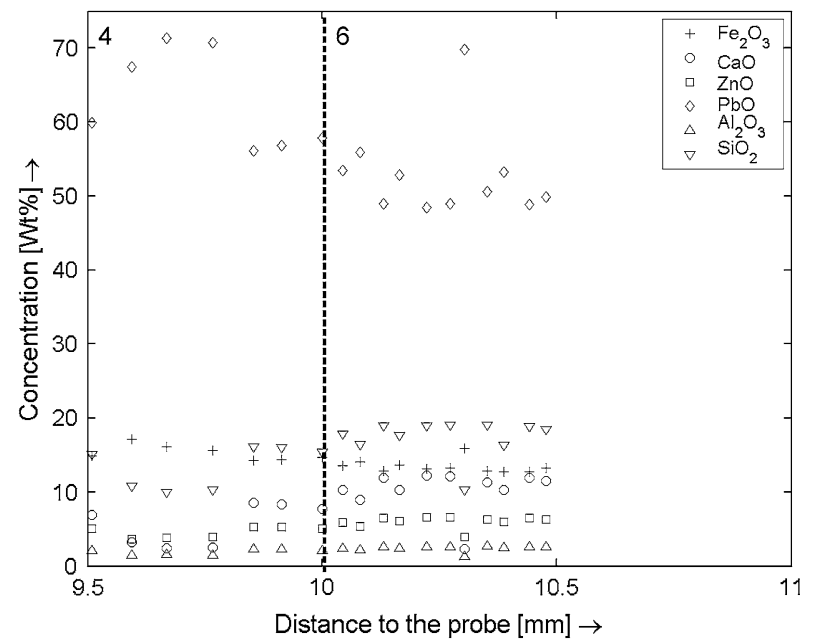

(a)

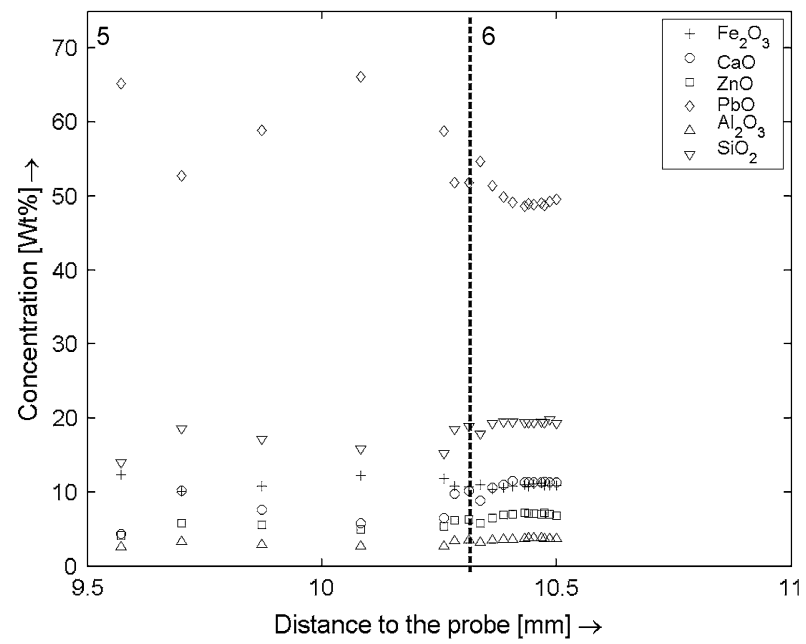

(b)

Fig. 7-Detail of the composition of the glass phase as a function of distance to the probe for $(a) 5$-min and $(b)$ 120-min freeze lining with the crystals-in-liquid (4), sealing-crystals (5), and entrained-slag-bath (6) layers.

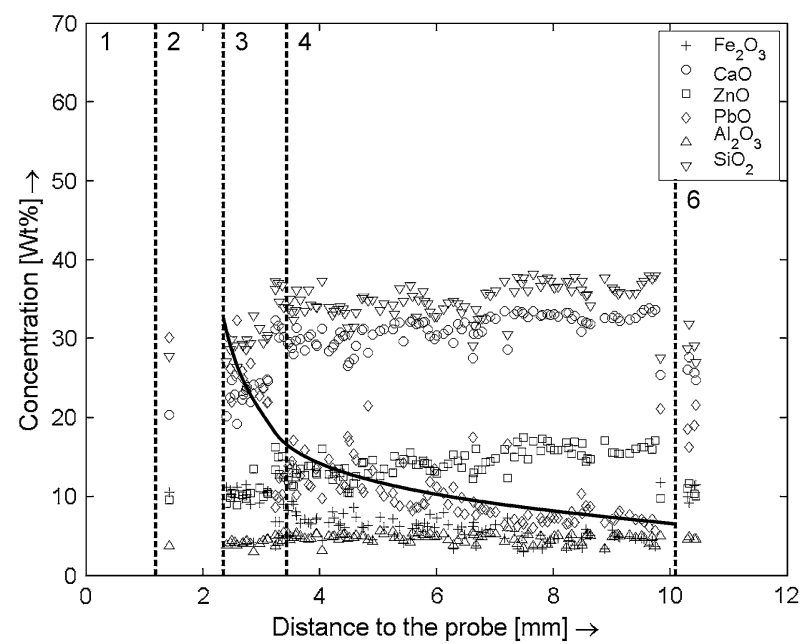

(a)

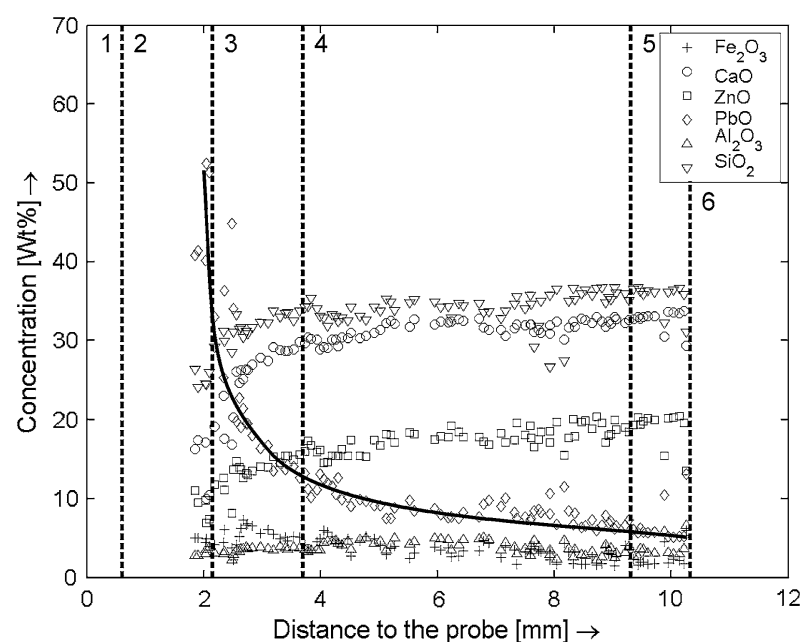

(b)

Fig. 8-Melilite composition as a function of distance to the probe for (a) 5-min and (b) 120-min freeze lining with the (1) glass, (2) glass-withcrystals, (3) crystalline, (4) crystals-in-liquid, (5) sealing-crystals, and (6) entrained-slag-bath layers. The full line indicates the PbO concentration.

in melilite strongly decreases from 30 to $55 \mathrm{wt}$ pct in the crystalline layer (3), to $5 \mathrm{wt}$ pct at the bath-freeze-lining interface (bath side of layer (5)), while the $\mathrm{CaO}$ concentration increases from 15 to $20 \mathrm{wt}$ pct to $35 \mathrm{wt}$ pct. The large melilite crystals in the glass and glass-with-crystal layers ((1) and (2)) have a very low $\mathrm{PbO}$ concentration, similar to the crystals at the bathfreeze-lining interface. These large melilite crystals are not observed in the 5- and 120-minute freeze linings. The composition evolution within one melilite crystal 
Table IV. Average Melilite Composition \pm Standard Deviation in the Six Layers Distinguished in the Freeze Lining for the 120-Minute Experiment

\begin{tabular}{lcccccc}
\hline Wt Pct & $\mathrm{CaO}$ & $\mathrm{SiO}_{2}$ & $\mathrm{PbO}$ & $\mathrm{ZnO}$ & $\mathrm{Fe}_{2} \mathrm{O}_{3}$ & $\mathrm{Al}_{2} \mathrm{O}_{3}$ \\
\hline$(1)$ & - & - & - & - & - & - \\
$(2)$ & - & - & - & - & - & - \\
$(3)$ & $16.2 \pm 4.4$ & $26.6 \pm 2.7$ & $39.5 \pm 8.6$ & $9.9 \pm 2.1$ & $4.7 \pm 0.6$ & $3.1 \pm 0.3$ \\
$(4)$ & $30.8 \pm 2.5$ & $34.1 \pm 1.8$ & $10.5 \pm 4.9$ & $17.2 \pm 2.1$ & $3.6 \pm 1.4$ & $3.7 \pm 0.8$ \\
$(5)$ & $32.8 \pm 0.9$ & $35.7 \pm 1.2$ & $6.2 \pm 1.7$ & $19.4 \pm 1.5$ & $2.4 \pm 1.0$ & $3.5 \pm 0.9$ \\
$(6)$ & - & - & - & - & - & - \\
\hline
\end{tabular}

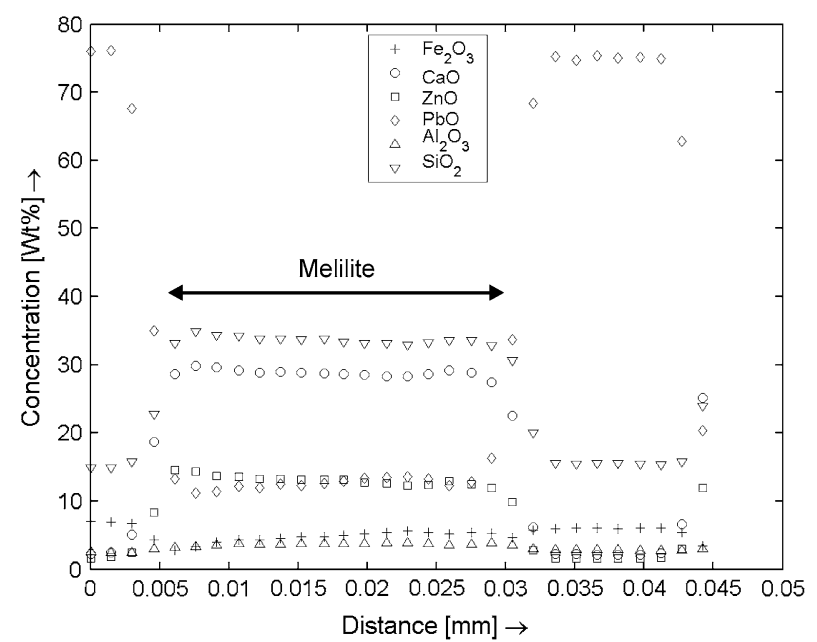

(a)

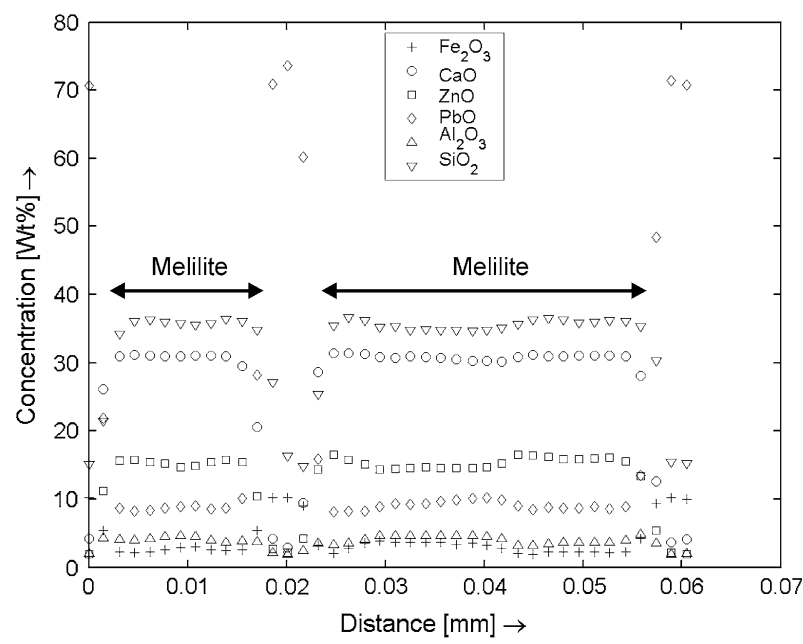

(b)

Fig. 9-Composition evolution within a melilite crystal in the crystals-in-liquid layer (4) of the 120-min freeze lining at (a) $4 \mathrm{~mm}$ and (b) $6.9 \mathrm{~mm}$ from the probe.

(parallel to the probe) was also analyzed (Figure 9). Here, no composition gradient (concentration difference less than 1 wt pct for $\mathrm{PbO}$ and for $\mathrm{CaO}$ ) in the melilite crystals is observed.

\section{Reference Experiments}

The isothermal annealing experiments show that crystallization is limited below $800{ }^{\circ} \mathrm{C}$ after 120 minutes. At $800{ }^{\circ} \mathrm{C}$, a fine eutectic-type microstructure containing melilite and spinel crystals is formed, as shown in Figure 10. Large melilite crystals with the same composition and morphology as the ones in the slag-bath samples are also observed. Above $800{ }^{\circ} \mathrm{C}$, crystallization happens rather quickly. At $900{ }^{\circ} \mathrm{C}$, the slag is almost fully crystalline after 60 minutes (Figure 10). Melilite, spinel, $\mathrm{PCSi}$, and $\mathrm{PbFe}$-silicate crystals are observed, including large melilite crystals and a fine eutectic-type microstructure containing melilite and spinel crystals. The large melilite crystals, which are similar to the ones in the bath samples, have a low $\mathrm{PbO}$ concentration. Above $900{ }^{\circ} \mathrm{C}$, glass, spinel crystals, small melilite crystals, and large melilite crystals, similar to the ones in the bath samples, are observed in the samples. The small melilite crystals are again only observed as a part of the eutectic-type microstructure. At $1200{ }^{\circ} \mathrm{C}$, only spinel crystals are stable in the liquid. Unfortunately, the composition of the small melilite crystals in all samples could not be measured. The average composition of the glass phase as a function of the annealing temperature is shown in Table $\mathrm{V}$ for the 120-minute experiments. Note that, thus, in the quench experiments, two types of melilite crystals are also observed.

The microstructures formed in the 120-minute cooling experiments are shown in Figure 11. When the final temperature was $800{ }^{\circ} \mathrm{C}$, melilite and spinel crystals with in-between $\mathrm{PbFe}$-silicate and PCSi crystals and glass phase are observed (the latter two phases are difficult to distinguish with LOM). For a final temperature of $900{ }^{\circ} \mathrm{C}$, the microstructure is similar; here, however, no PCSi crystals formed. For a final temperature of $1000{ }^{\circ} \mathrm{C}$, only melilite and spinel crystals formed. In the 15-minute experiment, the sample is quenched at a temperature of approximately $1100{ }^{\circ} \mathrm{C}$. In this sample, melilite and spinel crystals are observed. For all experiments, the cores (central parts) of the melilite crystals have close compositions (Table VII); this indicates that the diffusion in melilite crystals is slow and the composition of the melilite changes very slowly after the crystal is formed. Sometimes, at the melilite-glass interface, a very small composition gradient (an increase in $\mathrm{PbO}$ and a decrease in other components) is observed, as shown in Figure 12 for the $800{ }^{\circ} \mathrm{C}$ and $1000{ }^{\circ} \mathrm{C}$ final temperatures at the right side of the melilite crystal. 

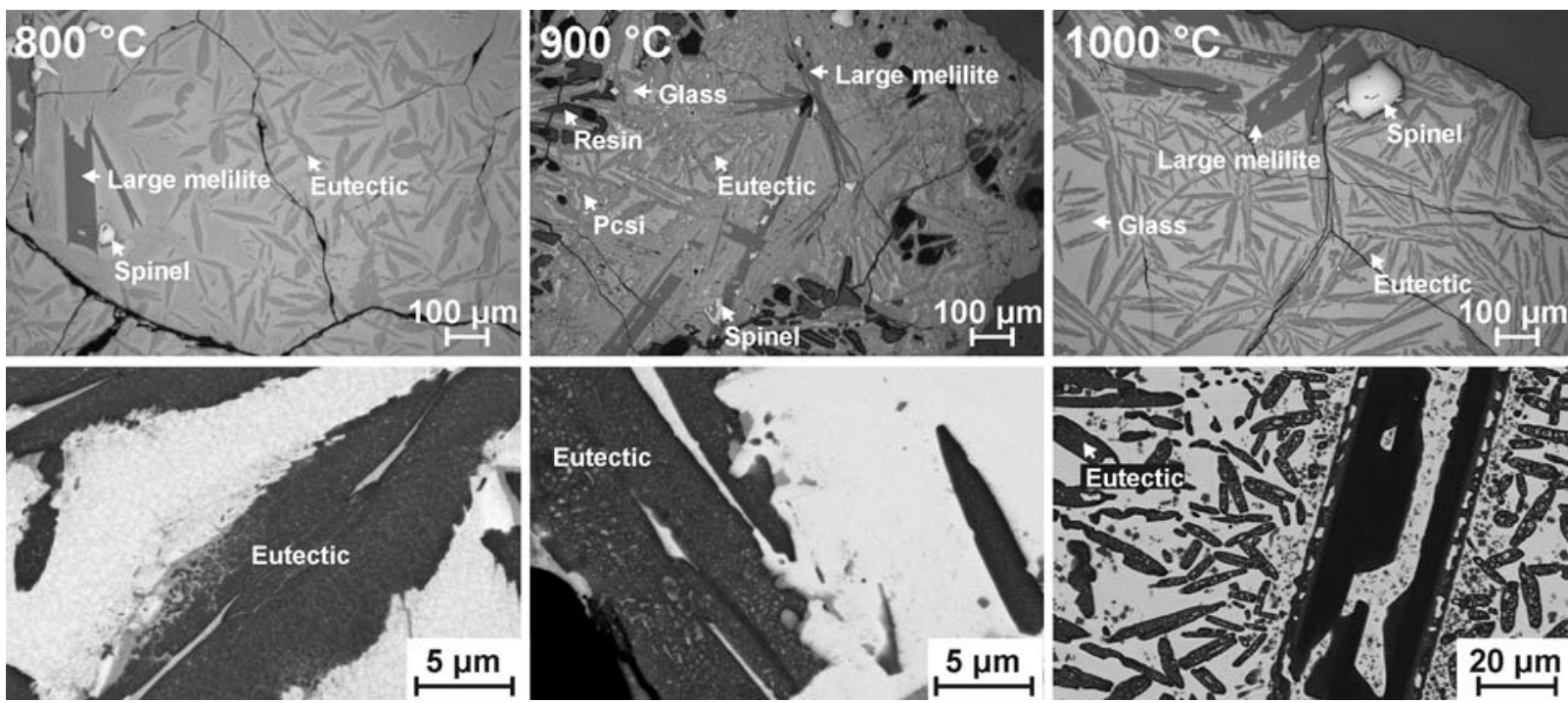

Fig. 10-Microstructures of the isothermal annealing experiments for 60 min at $800{ }^{\circ} \mathrm{C}, 900{ }^{\circ} \mathrm{C}$, and $1000{ }^{\circ} \mathrm{C}$. LOM images (top) and SEM-BSE images (bottom) are shown. The eutectic-type microstructure contains melilite and spinel crystals.

The variation in the measured composition in the area close to the melilite-glass interface is most likely the artifact of the EPMA analysis when the takeoff volume (the volume-generating characteristic X-rays measured in the analysis) contains both melilite and glass phases.

Table V. Average Glass Composition in Annealing Experiments

\begin{tabular}{lrrrrrr}
\hline Wt Pct & $\mathrm{CaO}$ & $\mathrm{SiO}_{2}$ & $\mathrm{PbO}$ & $\mathrm{ZnO}$ & $\mathrm{Fe}_{2} \mathrm{O}_{3}$ & $\mathrm{Al}_{2} \mathrm{O}_{3}$ \\
\hline $800{ }^{\circ} \mathrm{C}$ & 9.1 & 16.7 & 58.4 & 4.4 & 9.8 & 1.7 \\
$900{ }^{\circ} \mathrm{C}$ & 5.3 & 16.1 & 62.6 & 3.8 & 9.7 & 2.5 \\
$1000^{\circ} \mathrm{C}$ & 5.7 & 14.7 & 64.8 & 2.6 & 10.3 & 1.9 \\
$1100^{\circ} \mathrm{C}$ & 7.4 & 15.7 & 59.7 & 4.3 & 10.9 & 2.1 \\
$1200{ }^{\circ} \mathrm{C}$ & 12.0 & 18.9 & 46.5 & 8.2 & 12.1 & 2.4 \\
\hline
\end{tabular}

Note that the spatial resolution of the EPMA depends on the $Z$ factor of the matrix and is expected to be less than $1 \mu \mathrm{m}$ for the lead-containing phases. Note that, here, only one type of melilite crystals is observed similar to that in the crystalline (3), the crystals-in-liquid (4), the sealing-crystals (5), and the retrained-slag-bath (6) layers. The average glass and melilite compositions of the cooling experiments are shown in Tables VI and VII respectively.

\section{DISCUSSION}

First, the phase formation in the freeze lining is described, focusing on the glass-liquid interface in the
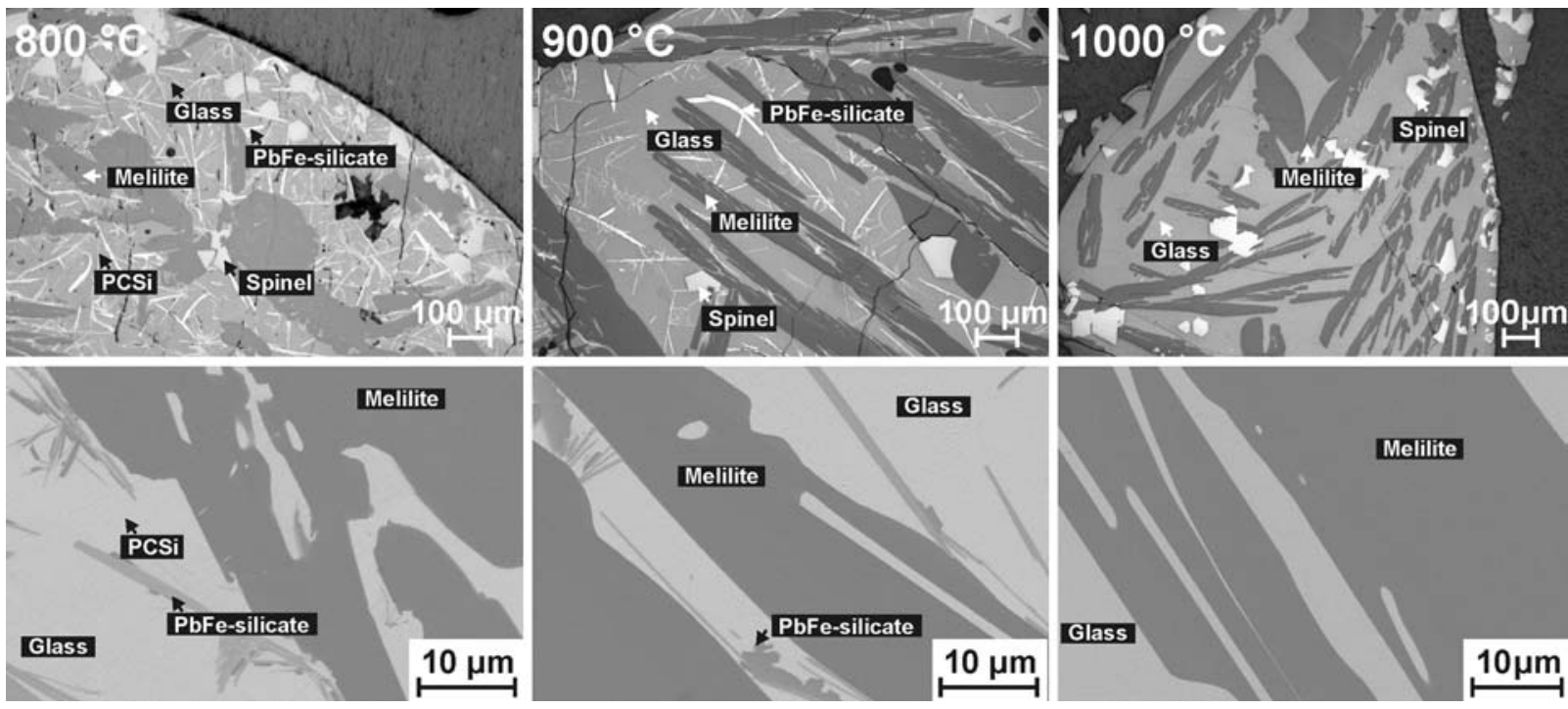

Fig. $11-$ Microstructures of the 120 -min cooling experiments with final temperatures at $800{ }^{\circ} \mathrm{C}, 900{ }^{\circ} \mathrm{C}$, and $1000{ }^{\circ} \mathrm{C}$. LOM images (top) and SEM-BSE images (bottom) are shown. 


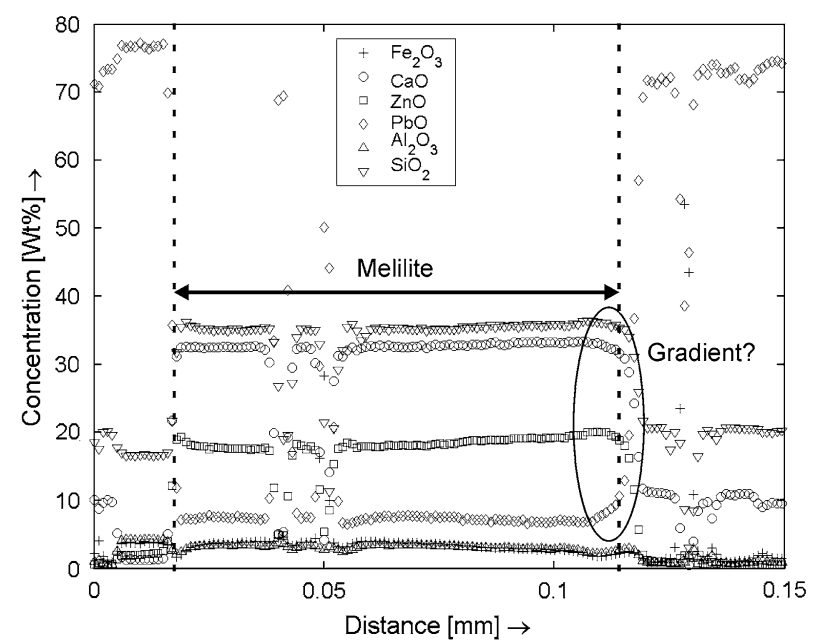

(a)

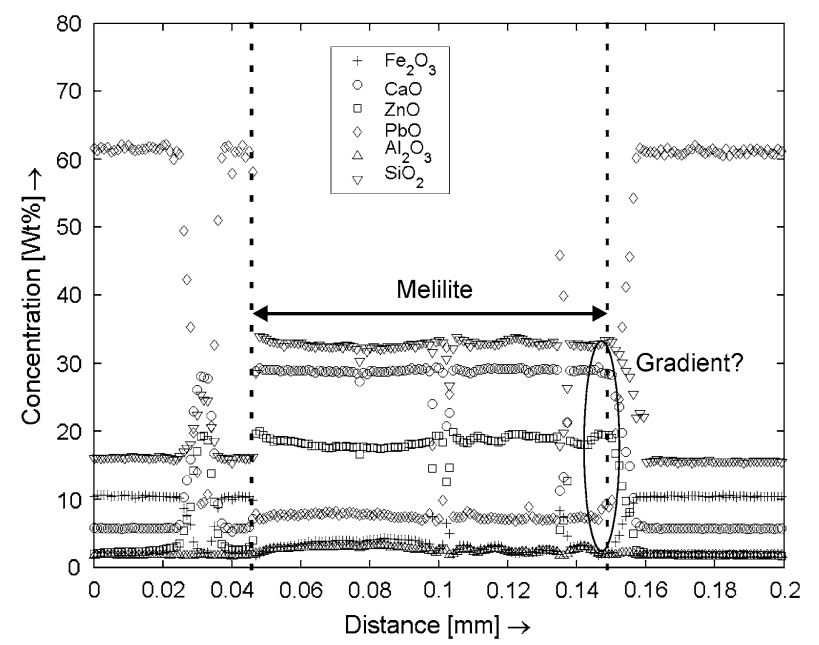

(b)

Fig. 12- Composition evolution in the melilite crystals of the cooling experiments with final temperatures $(a) 800{ }^{\circ} \mathrm{C}$ and $(b) 1000{ }^{\circ} \mathrm{C}$ for $120 \mathrm{~min}$. The dashed line indicates the interface between the melilite and glass/liquid.

Table VI. Average Glass Composition in Cooling Experiments

\begin{tabular}{lrrrrrc}
\hline Wt Pct & $\mathrm{CaO}$ & $\mathrm{SiO}_{2}$ & $\mathrm{PbO}$ & $\mathrm{ZnO}$ & $\mathrm{Fe}_{2} \mathrm{O}_{3}$ & $\mathrm{Al}_{2} \mathrm{O}_{3}$ \\
\hline $15 \mathrm{~min}$ & 12.0 & 19.1 & 47.0 & 7.5 & 12.0 & 2.4 \\
$800{ }^{\circ} \mathrm{C}$ & 7.7 & 19.2 & 68.7 & 0.5 & 2.0 & 1.9 \\
$900{ }^{\circ} \mathrm{C}$ & 3.4 & 13.9 & 71.1 & 1.7 & 8.1 & 1.9 \\
$1000{ }^{\circ} \mathrm{C}$ & 6.0 & 16.3 & 62.8 & 2.3 & 10.7 & 2.0 \\
\hline
\end{tabular}

Table VII. Average Melilite Composition in Cooling Experiments

\begin{tabular}{lcccccc}
\hline Wt Pct & $\mathrm{CaO}$ & $\mathrm{SiO}_{2}$ & $\mathrm{PbO}$ & $\mathrm{ZnO}$ & $\mathrm{Fe}_{2} \mathrm{O}_{3}$ & $\mathrm{Al}_{2} \mathrm{O}_{3}$ \\
\hline $15 \mathrm{~min}$ & 34.3 & 35.6 & 6.3 & 17.7 & 3.2 & 2.9 \\
$800{ }^{\circ} \mathrm{C}$ & 33.2 & 35.5 & 7.9 & 18.5 & 2.3 & 2.5 \\
$900{ }^{\circ} \mathrm{C}$ & 33.2 & 35.0 & 7.7 & 18.2 & 2.9 & 3.1 \\
$1000{ }^{\circ} \mathrm{C}$ & 31.1 & 34.8 & 8.1 & 19.7 & 3.3 & 3.1 \\
\hline
\end{tabular}

freeze lining and on the sequence of crystal formation. Next, the mass transport in the melilite crystals and in the glass/liquid phase during freeze-lining formation is discussed. Then, the freeze-lining formation is treated. Finally, the relevance of the results for industrial freezelining applications is considered.

\section{A. Phases in Freeze Lining}

\section{Glass phase}

The glass phase at room temperature was glass or liquid before quenching the lab-scale freeze lining. After quenching, all liquid transformed into glass and no clear interface between glass and former liquid is observed. However, this interface can be traced by microstructural analysis. Crystallization is optimal if the temperature is sufficiently low (below liquidus temperature) to have adequate crystal nucleation and sufficiently high to permit adequate kinetics for the crystals to grow. ${ }^{[15]}$
Here, a lower limit is the glass-transition temperature at which the mobility of the atoms strongly decreases during cooling. Note that, because liquid slag may be highly viscous above the glass-transition temperature, crystallization can be limited at higher temperatures. This implies that, for the freeze lining in the area with limited crystal growth, the glass phase at room temperature was most likely glass or highly viscous liquid before quenching the lab-scale freeze lining. In the glasswith-crystals layer (2) or at the glass-with-crystals (2) and crystalline (3) layer interface, there is a rather abrupt increase in the crystal size (Figure 4). Furthermore, for the current slag, the composition of the glass phase strongly differs from the bath composition, when crystallization occurs extensively. When looking at the composition of the glass phase of the 5- and 120-minute freeze linings, there is an abrupt change in the glass composition at the glass-with-crystal (2) and crystalline (3) layer interface. Thus, around the crystals-in-glass (2) and crystalline (3) layer interface, there is a change in mobility of the atoms that results in faster crystal growth, which is most likely due to a change from the glass or highly viscous liquid to a (more fluid) liquid. Therefore, in the freeze-lining microstructures, a distinction is made between a glass layer with crystals and a layer of crystals in liquid (Figure 4). Further, note that the term "glass phase" also includes highly viscous liquid.

\section{Crystalline phases}

In the freeze-lining microstructures (Figure 4), four crystalline phases are observed: spinel, melilite, $\mathrm{PbFe}-$ silicate, and PCSi. The spinel crystals are present in all layers that contain crystals. Most spinel crystals are entrapped in the other crystals. Therefore, the spinel crystals are assumed to form first. This assumption is supported by the isothermal annealing experiments, which show spinel to be the primary phase, and the FactSage calculations, which predict spinel to be the 
primary phase for all initial and final bath compositions. Melilite is thought to be formed second, because no $\mathrm{PbFe}$-silicate and PCSi crystals are entrapped in the melilite crystals. In the glass (1) and glass-with-crystals (2) layers, large $\mathrm{PbO}$-poor crystals and small $\mathrm{PbO}$-rich crystals are distinguished. The large $\mathrm{PbO}$-poor crystals are only observed in the case in which the slag-bath samples contain similar crystals. Furthermore, apart from small $\mathrm{PbO}$-rich crystals, large $\mathrm{PbO}$-poor crystals are also observed in the isothermal annealing experiment samples; they are not observed in the cooling experiment samples, which use premelted slag. Therefore, these large $\mathrm{PbO}$-poor melilite crystals were most likely already present in the slag bath and did not form during freeze-lining growth. The $\mathrm{PbFe}$-silicate crystals seem to form third, because they are entrapped in the PCSi crystals in the crystalline layer (3) and at the probe side of the crystals in the liquid layer (4). Most PbFesilicate crystals grow on top of spinel crystals. As the last phase, PCSi forms in the crystalline layer (3) and at the probe side of the crystals-in-liquid layer (4).

\section{B. Mass Transport}

\section{Mass transport in melilite crystals}

Figure 8 shows that the $\mathrm{PbO}$ and $\mathrm{CaO}$ concentrations strongly change with distance to the probe, due to the increasing $\mathrm{PbO}$ solubility in melilite with decreasing temperature ( $\mathrm{Ca}$ and $\mathrm{Pb}$ are both positioned in the $A$ site in melilite $\left(A_{2} \mathrm{BC}_{2} \mathrm{O}_{7}\right)$ and can replace each other). An important issue in determining the freeze-lining formation behavior is the question whether the melilite crystals form in an undercooled liquid or $\mathrm{PbO}$-poor melilite crystals form first and their composition changes thereafter by diffusion of $\mathrm{PbO}$ from the liquid into the melilite. To determine the mechanism, the composition evolution through the melilite crystals has been studied (Figure 9). A gradient from high $\mathrm{PbO}$ content at the crystal-liquid interface to a low $\mathrm{PbO}$ content in the center of the crystals indicates either that the center of the crystal is formed at a temperature higher than that of the outside of the crystals or that $\mathrm{PbO}$ diffused in the $\mathrm{PbO}$-poor melilite crystals with further cooling. This is, however, not observed; thus, either the melilite crystals form at a lower temperature or the diffusion in the solid phase occurs very quickly. To eliminate one of these possibilities, reference experiments are performed. In the isothermal annealing experiments, two types of melilite crystals are observed. The large crystals were already present in the bath and have a low $\mathrm{PbO}$ content. If the diffusion in the solid melilite phase occurs quickly, the composition of these large melilite crystals should change with the isothermal annealing temperature, which is not observed. Also, in the cooling experiments, the melilite crystals, which formed before the final temperatures were reached, have the same composition for different final temperatures, and no gradient is measured at the crystal-glass/liquid interface (Figure 12). The latter result is rather strange, because FactSage predicts an increase in the $\mathrm{PbO}$ content with decreasing temperature. The lack of a gradient seems to indicate that the melilite crystals are not in equilibrium with the liquid. Perhaps only a very small PbO-rich melilite layer formed at the outside of the crystals that was too small to measure or the kinetics were too slow. From these results, it can be concluded that no extensive diffusion of $\mathrm{PbO}$ from the liquid/glass in the crystals occurs. Therefore, the authors believe that the small melilite crystals in layer (2) and the melilite crystals in layers (3) through (5) most likely form in an undercooled liquid. Part $\mathrm{II}^{[16]}$ of this article more extensively discusses the melilite formation and the undercooling of the liquid.

\section{Mass transport in glass/liquid phase}

The mass transport during freeze-lining formation determines the mass exchange between the freeze lining and the bath and, in most cases, the crystal growth rate. Here, only the mass exchange between the freeze lining and the bath (referred to in previous research ${ }^{[13]}$ as longrange mass transfer) is discussed, because this determines the freeze-lining composition. In order for the mass exchange between the freeze lining and the bath to occur, components rejected by the crystals have to be transported to the bath by diffusive or convective mass transport.

In the case of diffusive mass transport, the diffusion rate has to be larger than the solidification rate. To estimate its impact, the penetration depth by diffusion can be estimated for a given diffusion coefficient. ${ }^{[20]}$ This penetration depth is defined as the distance at which the change in composition is a fixed percentage of the overall composition difference. For the studied system, the diffusion coefficient $(D)$ at $1200{ }^{\circ} \mathrm{C}$ is estimated at approximately $10^{-10}$ to $10^{-11} \mathrm{~m}^{2} / \mathrm{s}$, for the most quickly diffusing ions. ${ }^{[21]}$ With these values, the diffusion results in penetration depths $(x)$ of 0.56 and $0.18 \mathrm{~mm}$, respectively, for a 1 pet change in composition and of 0.43 and $0.14 \mathrm{~mm}$, respectively, for a 5 pct change in composition in a time $(t)$ of 5 minutes (using a percentage change $=$ $\operatorname{erfc}(x / \sqrt{4 D t}) \cdot 100)$, as shown in Figure 13. Because the freeze lining grows $10 \mathrm{~mm}$ in the first 5 minutes (Figure 3), the solidification rate is most likely higher than the diffusion rate. Furthermore, the Lewis number, ${ }^{[2]}$ used to compare the impact of the heat and mass transfer, can be estimated for the slag as

$$
\text { Le }=\frac{\alpha}{D}=\frac{k /\left(\rho \cdot c_{p}\right)}{D}=\frac{2 /(5000 \cdot 100)}{10^{-10}}=4 \cdot 10^{4}
$$

with $\alpha$ the heat diffusivity of the slag, $k$ the heat conductivity of the slag, $\rho$ the density of the slag, $c_{p}$ the heat capacity of the slag, and $D$ the diffusion coefficient in the slag. Here $k, \rho, c_{p}$, and $D$ are estimated to be $2 \mathrm{~W} /$ $\mathrm{mK}^{[21]} 5000 \mathrm{~kg} / \mathrm{m}^{3},{ }^{[21]} 100 \mathrm{~J} / \mathrm{kgK}$ (FactSage), and $10^{-10} \mathrm{~m}^{2} / \mathrm{s},{ }^{[21]}$ respectively. The Lewis number is very high $(>>1)$, indicating that the mass transfer by diffusion is much slower than the heat transfer. Also, the melilite crystal composition shows that the crystals form in undercooled liquid. Therefore, for a freeze-lining thickness of between 0 and $8 \mathrm{~mm}$, the diffusion coefficient is lower than that used for the penetration-depth estimations. As a result, the mass exchange between the freeze lining and the bath during this first 5 minutes is 


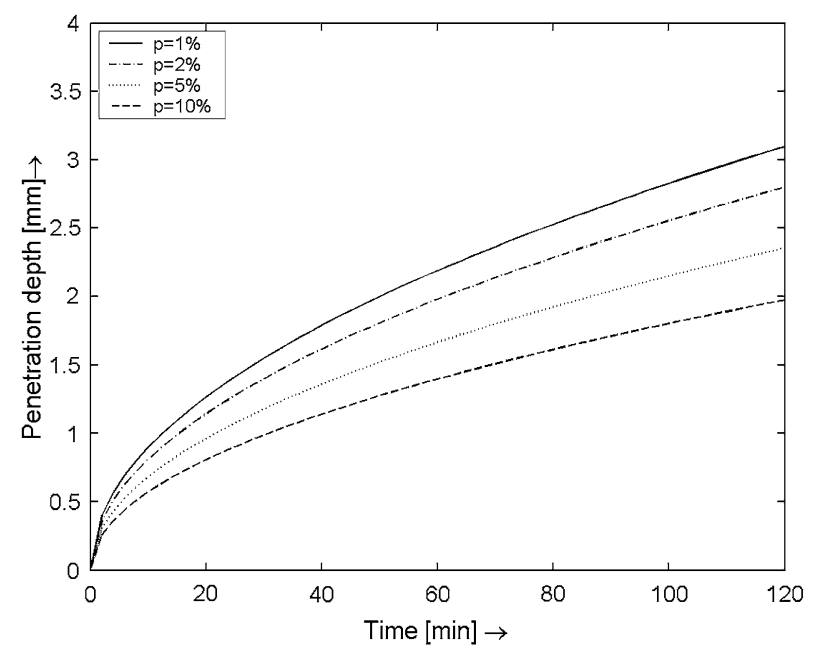

(a)

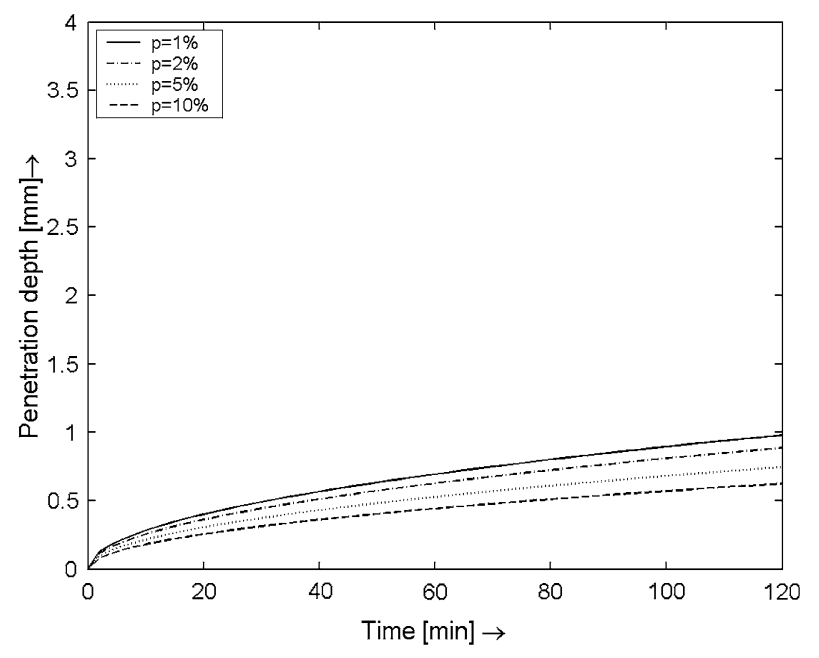

(b)

Fig. 13-Penetration depth as a function of time for different percentage changes in composition and for a diffusion coefficient of $(a) 10^{-10} \mathrm{~m} / \mathrm{s}^{2}$ and $(b) 10^{-11} \mathrm{~m} / \mathrm{s}^{2}$.

considered to be limited. Also, the melilite crystals are long and thin, with a large amount of liquid in between; thus, a large amount of liquid is available in between the crystals for exchanging components. ${ }^{[13]}$ When the freezelining approaches its steady-state thickness, the effect of diffusion becomes more important. Between 5 and 30 minutes, the freeze-lining thickness increases approximately $1 \mathrm{~mm}$. The penetration depth is now of comparable size for values of $D$ of approximately $10^{-10}$ and $10^{-11} \mathrm{~m}^{2} / \mathrm{s}$; thus, the mass exchange between the freeze lining and the bath has to be considered. In the sealingcrystal layer (5), the melilite crystals (and also the spinel crystals) are large and broad, with a limited amount of liquid in between; thus, they can only grow by mass exchange between the bath and the freeze lining. ${ }^{[13]}$

In the case of convective mass transfer, rejected components are removed by liquid movement in the bath. The studied system has the advantage that the color of the glass in the microstructure strongly changes with the $\mathrm{PbO}$ content: light-colored glass contains more $\mathrm{PbO}$ than dark-colored glass. The glass at the bath-freeze-lining interface for the 5- and 15-minute freeze linings is very inhomogeneous (Figures 4 and 5, respectively). These inhomogeneities seem to result from mixing the $\mathrm{PbO}$-rich liquid at the crystal-liquid interface with the bath liquid, resulting in long-range mass transport between the freeze lining and the slag bath. This mixing is most likely enhanced by the density differences between the PbO-rich (highdensity) and $\mathrm{PbO}$-poor (low-density) liquid. Furthermore, the crucible is rotating during the experiment, resulting in the mixing of the bath. However, in previous research, ${ }^{[13]}$ it is indicated that, for the applied rotation speed, the effect of the natural convection is stronger or in the same range as the forced convection. Nevertheless, the forced convection contributes in some degree to convective mass transfer. Thus, the freeze-lining composition at the bath side (between approximately 8 to 9 and $10.5 \mathrm{~mm}$ ) is affected by convective mass transport.

\section{Freeze-Lining Formation}

\section{Freeze-lining formation evaluated by comparing} with reference experiments

By comparing the results of the reference experiments, which were subjected to a known heat treatment, with the results of the freeze-lining experiments, the formation of the freeze lining can be evaluated. The isothermal annealing experiments assume that, in the freeze lining, the liquid is first cooled very quickly to a fixed temperature, followed by annealing at that temperature. The microstructures of the isothermal annealing samples differ strongly from the freeze-lining microstructures in the crystal morphology. The melilite crystals in the isothermal annealing experiments seem to be formed by an eutectic reaction, because they entrap liquid and small crystals that are homogeneously distributed. In the freeze lining, no eutectic microstructure is observed. Also, the size of the PCSi and the PbFe-silicates crystals in the isothermal annealing experiments is much smaller than in the freeze lining. In the cooling experiments, a part of the crystals forms during fast cooling to a fixed temperature. Further crystallization occurs during annealing at that temperature. The microstructures of the crystals in the liquid layer and of the cooling experiments are very similar. Thus, the cooling experiments better simulate the formation of the crystals in the liquid layer, as long as the overall composition of the freeze lining locally equals the bath composition. The cooling experiments, however, are performed for only one cooling rate $\left(10^{\circ} \mathrm{C} / \mathrm{min}\right.$, corresponding to the local cooling rate approximately $1 \mathrm{~cm}$ from the probe, according to the temperature measurements ${ }^{[16]}$, resulting in one melilite composition in all experiments. In the freeze lining, the melilite composition changes in the 
crystals-in-liquid layer (4) with distance to the probe, indicating that the cooling rate at which the melilite crystals form differs.

\section{Freeze-lining formation evaluated by study of microstructural data}

After submerging the probe, a layer of rapidly quenched glass (1) immediately forms on the probe. Because this layer (1) remains at a low temperature, the crystallization of the glass phase after 120 minutes is limited. Sometimes, large crystals (here, melilite and spinel) are observed in this layer. They were already present in the slag bath. The next layer (2) that forms is less rapidly cooled, because the probe is insulated by the first layer. ${ }^{[12]}$ As a result, small equiaxed crystals can form. With increasing submerging time, more crystals appear in this crystals-in-glass layer (2). Further from the probe, the local temperature is higher and the glass phase in these layers is believed to be liquid at high temperature. Here, the growth of the freeze lining is determined by the formation of a sticky, highly viscous liquid layer or by the growth of crystals in liquid. If a layer of sticky, highly viscous liquid slag is part of the freeze lining, the temperature profile determines the freeze-lining thickness. If no such layer forms or if the slag easily crystallizes, crystal growth controls the further growth of the freeze lining. For the studied slag, after 1 minute, extensive crystallization has already occurred in the freeze lining. Thus, the glass layer and the highly viscous liquid layer only determine the freezelining growth in the first seconds (minute). The spinel phase, although the primary phase, forms separate crystals that do not interconnect. The melilite phase, however, forms interconnecting crystals and dominates the microstructure. As a result, the further growth of the freeze lining is believed to be determined by the growth of the melilite crystals in the liquid slag. Close to the probe, the melilite crystals have a random orientation. Further from the probe, starting from approximately 4 to $5 \mathrm{~mm}$, the melilite crystals show columnar growth parallel to the heat flux. The columnar growth indicates that a concentration gradient is present in the liquid at the bath-freeze-lining interface (constitutional undercooling $\left.{ }^{[15]}\right)$. The crystals form in undercooled liquid; therefore, it is most likely that the mass exchange between the bath and the freeze lining is limited and that most of the rejected components and liquid are entrapped between the columnar crystals. The exchanged amount increases when the freeze lining becomes thicker, because the solidification rate decreases. When the solidification rate gets sufficiently low compared to the mass-transfer rate, extensive mass exchange between the freeze lining and the bath occurs. Here, the melilite crystals grow large and a layer of sealing crystals (5) forms. In this layer, the spinel crystals also grow large. After 120 minutes, the crystals in this layer (5) are still growing, indicating that steady state is not yet reached. Perhaps, after longer submergence times, a layer of spinel crystals will form at the bath-freeze-lining interface, because the spinel phase is stable at a higher temperature than the melilite crystals. Close to the probe, the local temperature is high enough to allow further crystallization (devitrification) of the glass or (high-viscosity) liquid, resulting in the formation of a fully crystalline layer in between the crystalsin-glass and crystals-in-liquid layers.

\section{Implications for Freeze-Lining Applications}

For freeze-lining formation, the results show that, first, a glass layer and a layer of highly viscous liquid forms. The thickness of these layers depends on the local temperature profile. Further growth of the freeze lining is controlled by the crystallization of the highly viscous layer and by the crystal growth in liquid. The studied slag easily forms crystals; thus, the formation of a glass layer and a highly viscous liquid layer is only important in the beginning of the freeze-lining formation. For crystal growth, a distinction has to be made between a crystalline phase forming interlocking crystals and a crystalline phase forming separate crystals. Interlocking crystals are needed to stabilize a freeze-lining layer. For the studied slag, the melilite phase is the interlocking phase; thus, the growth of melilite crystals determines further freeze-lining growth. The spinel phase, although the primary phase, forms separate crystals and does not stabilize the layer for the studied slag.

The freeze-lining composition differs from the bath composition at low solidification rates only. For the present slag, the freeze lining is expected to deviate significantly from the bath composition at the bathfreeze-lining interface in the sealing-crystals layer (5).

The studied slag rapidly forms a freeze lining; in 5 minutes, the steady-state thickness is almost reached. In the slag, the melilite is stable at high temperature and over a wide temperature range. Because melilite rapidly forms crystals, the freeze lining grows rapidly after the formation of the glass and a highly viscous liquid layer. This suggests that, by slag engineering, the phases that form in the freeze lining can be optimized to obtain rapid freeze-lining formation.

\section{CONCLUSIONS}

The freeze-lining formation of a synthetic lead slag has been studied. The microstructure and phase composition in the freeze lining have been compared to the results of reference experiments, to determine the phase formation during freeze-lining growth. The studied slag rapidly forms a freeze lining. The initial growth of the freeze lining is determined by the immediate formation of a glass layer and a layer of highly viscous slag. After 1 minute, further growth of the freeze lining is controlled by the growth of melilite crystals in liquid. Because the heat transfer in the slag is very fast and the diffusion in the solid phase is limited, these melilite crystals form in undercooled liquid and their composition does not change after their formation. Mass exchange between the freeze lining and the bath is limited during the initial freeze-lining growth, because, here, the solidification rate is high. When the freezelining thickness almost reaches steady state, extensive mass exchange occurs. 
For freeze-lining applications, the results suggest that the solidification properties of the slag are important for rapid freeze-lining formation. The presence of a phase that rapidly forms interlocking crystals that are stable between the glass-formation temperature and high temperature seems to be favorable for rapid freezelining formation.

\section{ACKNOWLEDGMENTS}

The authors thank Umicore Research (Olen, Belgium), for its financial support, and especially Luc Coeck, Tim Verheyen, and Danny Leysen, for their help with the experimental work.

\section{REFERENCES}

1. L.R. Nelson, R. Sullivan, P. Jacobs, E. Munnik, P. Lewarne, E. Roos, M.J.N. Uys, B. Salt, M. de Vries, K. McKenna, N. Voermann, and B.O. Wasmund: J. S. Afr. Inst. Min. Metall., 2004, vol. 104 (9), pp. $551-61$.

2. D.G.C. Robertson and S. Kang: Fluid Flow Phenomena in Metals Processing, TMS, Warrendale, PA, 1999, pp. 157-68.

3. K. Verscheure, M. Van Camp, B. Blanpain, P. Wollants, P. Hayes, and E. Jak: Metall. Mater. Trans. B, 2007, vol. 38B, pp. 13-20.

4. K. Verscheure, M. Van Camp, B. Blanpain, P. Wollants, P. Hayes, and E. Jak: Metall. Mater. Trans. B, 2007, vol. 38B, pp. 21-33.

5. J.H. Zietsman and P.C. Pistorius: Miner. Eng., 2006, vol. 19, pp. $262-79$.

6. P.C. Pistorius: Proc. VII Int. Conf. on Molten Slags, Fluxes, and Salts, SAIMM, Johannesburg, South Africa, 2004, pp. 237-42.
7. P.C. Pistorius: J. S. Afr. Inst. Min. Metall., 2003, vol. 103 (8), pp. 509-14.

8. K.A. Rye, T. Eidet, and K. Tørklep: Light Metals 1999, TMS, Warrendale, PA, 1999, pp. 347-52.

9. C.C. Wei, J.J.J. Chen, B.J. Welch, and V.R. Voller: Light Metals 1997, TMS, Warrendale, PA, 1997, pp. 309-16.

10. A. Solheim and L.I.R. Støen: Light Metals 1997, TMS, Warrendale, PA, 1997, pp. 325-32.

11. J. Thonstad and S. Rolseth: Light Metals 1983, TMS-AIME, Warrendale, PA, 1983, pp. 415-23.

12. M. Campforts, K. Verscheure, E. Boydens, T. Van Rompaey, B. Blanpain, and P. Wollants: Metall. Mater. Trans. B, 2007, vol. $38 \mathrm{~B}$, pp. 841-51.

13. M. Campforts, K. Verscheure, E. Boydens, T. Van Rompaey, B. Blanpain, and P. Wollants: Metall. Mater. Trans. B, 2008, vol. 39B, pp. $408-17$.

14. K. Verscheure, M. Campforts, F. Verhaeghe, E. Boydens, M. Van Camp, B. Blanpain, and P. Wollants: Metall. Mater. Trans. B, 2006, vol. 37B, pp. 929-40.

15. W. Kurz and D.J. Fisher: Fundamentals of Solidification, 3rd ed., Trans Tech Publications, Aedermannsdorf, Switzerland, 1989.

16. M. Campforts, E. Jak, B. Blanpain, and P. Wollants: Metall. Mater. Trans. B, 2009, vol. 40B, doi:10.1007/s11663-009-9257-8.

17. C.W. Bale, P. Chartrand, S.A. Degterov, G. Eriksson, K. Hack, R. Ben Mahfoud, J. Melançon, A.D. Pelton, and S. Petersen: CALPHAD, 2002, vol. 26 (2), pp. 189-228, www.factsage.com.

18. S. Decterov, I.H. Jung, E. Jak, P. Hayes, and A.D. Pelton: Proc. VII Int. Conf. on Molten Slags, Fluxes, and Salts, SAIMM, Johannesburg, South Africa, 2004, pp. 839-50.

19. E. Jak, S. Degterov, B. Zhao, A.D. Pelton, and P.C. Hayes: Metall. Mater. Trans. B, 2000, vol. 31B, pp. 621-30.

20. F.P. Incropera and D.P. DeWitt: Fundamentals of Heat and Mass Transfer, 5th ed., John Wiley \& Sons, New York, NY, 2002, pp. $354-55$ and 891.

21. Verein Deutscher Eisenhüttenleute: Slag Atlas, 2nd ed., Verlag Stahleisen GmbH, Düsseldorf, Germany, 1995, pp. 313-48, 541-56, and 591-99. 